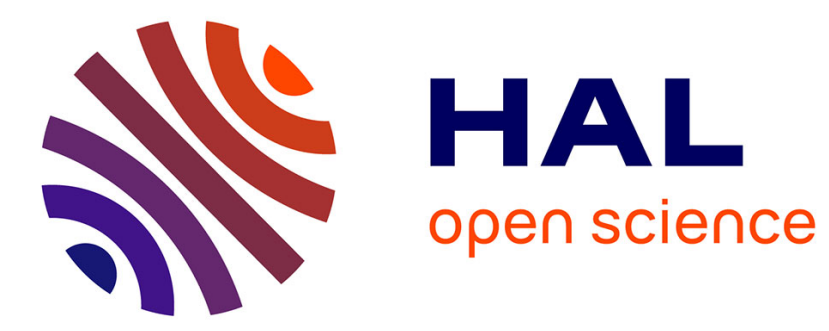

\title{
Kinetics of High Temperature Oxidation and Chromia Volatilization for HfC-Containing Nickel-Based Alloys
}

Elodie Conrath, Patrice Berthod

\section{To cite this version:}

Elodie Conrath, Patrice Berthod. Kinetics of High Temperature Oxidation and Chromia Volatilization for HfC-Containing Nickel-Based Alloys. Oxidation of Metals, 2014, 81 (3-4), pp.393-405. 10.1007/s11085-013-9449-0 . hal-02181307

\section{HAL Id: hal-02181307 \\ https://hal.science/hal-02181307}

Submitted on 12 Jul 2019

HAL is a multi-disciplinary open access archive for the deposit and dissemination of scientific research documents, whether they are published or not. The documents may come from teaching and research institutions in France or abroad, or from public or private research centers.
L'archive ouverte pluridisciplinaire HAL, est destinée au dépôt et à la diffusion de documents scientifiques de niveau recherche, publiés ou non, émanant des établissements d'enseignement et de recherche français ou étrangers, des laboratoires publics ou privés. 


\title{
Kinetics of High Temperature Oxidation and Chromia Volatilization for HfC-containing Nickel-based Alloys
}

\author{
Elodie Conrath and Patrice Berthod \\ Institut Jean Lamour (UMR CNRS 7198), Department CP2S, Faculty of Science and Technologies, Postal Box \\ 70239, 54506 Vandoeuvre-lès-Nancy, FRANCE \\ elodie.conrath@univ-lorraine.fr, patrice.berthod@centraliens-lille.org
}

\begin{abstract}
Many cast chromia-forming nickel-based superalloys are reinforced by carbides. In such alloys the primary chromium carbides or tantalum carbides rapidly lose their strengthening effect in service at high temperature because of decrease in volume fraction and morphology evolution. Other carbides, HfC for example, are more stable at high temperature and they can be candidates for the reinforcement of this type of superalloy. In this work, three nickel-based alloys containing $25 \mathrm{wt} \% \mathrm{Cr}, 0.25$ or $0.50 \mathrm{wt} . \% \mathrm{C}$, and $\mathrm{Hf}$ with contents high enough ( 3.7 and $5.6 \mathrm{wt} . \%$ ) to promote the formation of numerous primary HfC carbides, were elaborated by foundry. They were tested in oxidation by air during $46 \mathrm{~h}$ at $1200^{\circ} \mathrm{C}$, with thermogravimetry measurement and metallographic characterization. All the mass gain curves obtained are parabolic and the oxidation rates of the studied alloys are only slightly faster than for corresponding ternary nickel alloys containing the same chromium and carbon quantities. The obtained values of the parabolic constant $\mathrm{k}_{\mathrm{p}}$ and of the chromia volatilization constant $\mathrm{k}_{\mathrm{v}}$, deduced by applying the $\left\{\mathrm{m} \times \mathrm{dm} / \mathrm{dt}=\mathrm{k}_{\mathrm{p}}-\mathrm{k}_{\mathrm{v}} \times \mathrm{m}\right\}$ method, are typical of a chromia-forming behavior. However, small quantities of $\mathrm{HfO}_{2}$ and $\mathrm{NiCrTaO}_{4}$ oxides are noticed in addition to the chromia scale. In the bulk, the volume fraction and morphology of the HfC carbides only changed a little.
\end{abstract}

Keywords: Nickel-based alloys; HfC carbides; High temperature oxidation; Kinetic constants; Scale characteristics

Post-print version of the article Oxid Met (2014) 81:393-405; DOI 10.1007/s1 1085-013-9449-0

\section{INTRODUCTION}

The $\gamma / \gamma^{\prime}$ single crystal nickel-based superalloys are among the best refractory alloys for the applications at very high temperature [1]. Their high contents in aluminum allow them resisting high temperature oxidation by isolating the metallic alloy from the aggressive atmosphere with a protective continuous alumina scale [2]. In some cases a good resistance against corrosion by liquid substances (molten glass for example) is also required. In such case the alloys must contain at least twenty weight percents of chromium, with as consequence a decrease in their aluminum content to low values. An efficient strengthening by high volume fractions of $\gamma$ ' precipitates cannot be achieved in these conditions and the alloy's reinforcement must be ensured by other particles, primary carbides for example. These ones are generally chromium carbides [3] since, in cast chromium-rich nickel-based alloys, tantalum carbides are often much less stable than in cobalt-based alloys [4]. It was seen in a previous work that another type of MC carbides, hafnium mono-carbide, is thermally more stable than tantalum carbides when present in chromium-rich cobalt-based alloys [5]. In addition, in a more recent work, it was demonstrated that primary hafnium carbides can be successfully obtained in chromium-rich nickel-based alloys. As in cobalt alloys, during solidification, the HfC carbides precipitate in the interdendritic spaces of these nickel alloys, as script-like eutectic carbides mixed with matrix [6]. Thus, hafnium, the best known effect of which is the improvement of the behavior of superalloys in high temperature oxidation $[7,8]$, in terms of oxidation rate or oxide scales adherence for instance, is also able to provide carbides potentially efficient for the mechanical reinforcement of superalloys.

Paradoxically, the hafnium carbides were rarely used to mechanically reinforce alloys for high temperature applications. HfC were however considered, thirty years ago, in cobalt-based hard metals [9] or in directionally solidified nickel-based alloys [10] for example. HfC were more used in molybden-based [11] or tungsten-based [12] 
alloys. The goal was generally to improve the mechanical properties of these alloys. This was also the objective for the tensile properties [13] or the creep resistance [14] of (molybden, tungsten)-based alloys, as well as of (tungsten, rhenium)-based alloys [15-17]. In contrast it seems that no significant results are available about the oxidation at high temperature of alloys containing great fractions of hafnium carbides.

Hafnium is a highly oxidable element. Its presence in high temperature alloys in quantities significantly higher than what is generally added to improve their hot oxidation behavior, may conversely threaten the alloy's resistance to oxidation at high temperature. This is notably true for uses at very high temperature at which the high thermal stability of HfC alloys can be better exploited. The purpose of the present work is to verify this point. The high temperature oxidation behavior of cast chromium-rich nickel-based alloys containing significant quantities of HfC carbides has been explored by performing oxidation tests at $1200^{\circ} \mathrm{C}$ for three alloys of this type.

\section{EXPERIMENTAL}

The work started by the elaboration of three Hf-rich nickel-based alloys containing $25 \mathrm{wt} . \% \mathrm{Cr}, 0.25$ or 0.50 wt. $\% \mathrm{C}$ and 3.7 or $5.6 \mathrm{wt} . \% \mathrm{Hf}$. Two supplementary ternary alloys with the same chromium and carbon contents were also synthesized to allow comparisons with the three former alloys in order to better analyze the effect of these high hafnium quantities on the hot oxidation behavior. All the alloys were elaborated by melting pure elements (Alfa Aesar, purity > 99.9wt.\%) in a High Frequency induction furnace (CELES). Heating, melting, solidification and solid state cooling were realized under an inert atmosphere of 300mbars pure argon. Five compact-shaped ingots (weight: about $40 \mathrm{~g}$ ) were obtained. They were cut for preparing metallographic samples for examining the as-cast microstructure, and parallelepiped samples for the thermogravimetry tests (about $9 \times 9 \times 3 \mathrm{~mm}^{3}$ ). The metallographic samples were embedded in a cold resin mixture (resin CY230 + hardener HY956, ESCIL). They were polished with SiC-enriched papers with grade varying from 120 to 1200, cleaned by ultrasonic vibrations in water, and polished again with textile enriched with $1 \mu \mathrm{m}$-alumina particles until a mirror-like state was obtained. The parallelepiped samples were polished with SiC-papers (120 to 1200-grit) and their edges and corners were smoothed using 1200-grit paper.

The thermogravimetry samples were oxidized, with mass gain recording, using a SETARAM TGA92 thermobalance. The whole thermal cycle was performed in dry industrial air $\left(80 \% \mathrm{~N}_{2}-20 \% \mathrm{O}_{2}\right)$. It was composed of a heating at $+20^{\circ} \mathrm{C} / \mathrm{min}$, an isothermal dwell of $46 \mathrm{~h}$ at $1200^{\circ} \mathrm{C}$ and a cooling rate at $-5^{\circ} \mathrm{C} / \mathrm{min}$. The mass gain files were first plotted versus time to specify the kinetic character (parabolic or not). The mass gain per surface unit area (m) was then plotted versus the square root of time for the classical determination of the parabolic constant $\mathrm{k}_{\mathrm{p}}$. The mass gain files were also plotted and exploited according to the $\left\{\mathrm{m} \times \mathrm{dm} / \mathrm{dt}=\mathrm{k}_{\mathrm{p}}-\mathrm{k}_{\mathrm{v}} \times \mathrm{m}\right\}$ method [18] to take into account the probable volatilization of chromia in order to avoid underestimating the parabolic constant $\mathrm{k}_{\mathrm{p}}$. The chromia volatilization constant $\mathrm{k}_{\mathrm{v}}$ was determined by considering the slope of the linear part of the $\{(\mathrm{m} \times \mathrm{dm} / \mathrm{dt})$ plotted versus $(-\mathrm{m})\}$ graph and the parabolic constant $\mathrm{k}_{\mathrm{p}}$ was determined by considering the ordinate at the origin of this same linear part.

Post-mortem characterization of the oxidized samples was done after oxidation test. They were first scanned using a simple office scanner to get macrographs illustrating the oxide spallation during cooling, and subjected to XRay diffraction (Philips X'Pert Pro diffractometer) for analyzing the natures of the external oxides remaining on surface. The oxidized samples were thereafter covered by an electrolytic nickel layer for protecting the external oxide from possible damage during cutting. They were cut in two parts, embedded in cold resin mixture and polished to obtain a mirror-like surface, as described above for the metallographic samples for as-cast microstructure observation.

All observations were done using a Scanning Electron Microscope (SEM) JEOL JSM-6010LA in Back Scattered Electrons (BSE) mode. The control of the general chemical compositions of the alloys was realized on the metallographic samples with the Energy Dispersion Spectrometry (EDS) apparatus equipping the SEM. The same device was used for identifying the carbides in the bulks of the as-cast samples and of the oxidized samples, the internal oxides in the subsurface, and the external oxide scales. This EDS device was also used to measure the chromium contents in extreme surface. 


\section{RESULTS}

\section{The Studied Alloys}

The obtained chemical compositions of the studied alloys are given in Table 1 (measured by EDS). They are close to the targeted compositions. The determination by EDS was not possible for carbon because this element is too light and it is present in too low quantities in the studied alloys to be successfully analyzed by EDS. However, the obtained volume fractions of carbides showed that the targeted carbon contents were certainly well respected in each of the five alloys.

The as-cast microstructures of the alloys are illustrated by SEM/BSE micrographs in Figure 1. The two ternary alloys are composed of an austenitic dendritic matrix and of chromium carbides present in the interdendritic spaces. These carbides are of the $\mathrm{M}_{7} \mathrm{C}_{3}$ stoichiometry. They are logically more numerous in the $0.50 \mathrm{C}$-containing alloy than in the $0.25 \mathrm{C}$-containing alloy.

The three Hf-rich alloys are also composed of a dendritic matrix and of interdendritic carbides. The matrix is a solid solution of nickel which contains the whole chromium, or the main part of the total chromium quantity if the alloy contains also chromium carbides. In contrast Hf seems to be absent in matrix, as shown by the EDS pinpoint measurements. The carbides are present, all in the interdendritic spaces, in higher quantity in the 0.50C-containing alloys than in the $0.25 \mathrm{C}$-containing ones. These carbides are exclusively HfC (clearer than matrix in SEM/BSE mode) in the Ni-25Cr-0.25C+Hf and Ni-25Cr-0.50C++Hf alloys. This is in accordance with what was wished: the $\mathrm{Hf}$ and $\mathrm{C}$ weight contents were defined to have as many hafnium atoms as carbon atoms in these two alloys. In contrast, HfC are present together with chromium carbides in the $\mathrm{Ni}-25 \mathrm{Cr}-0.50 \mathrm{C}+\mathrm{Hf}$ alloy which contains more carbon atoms than hafnium Hf atoms.

\section{The Thermogravimetry Results}

The obtained mass gain curves are given in Figure 2, on the left for the two alloys containing 0.25 wt. $\% \mathrm{C}$ (the ternary alloy and the first Hf-rich one) and on the right for the three alloys containing $0.50 \mathrm{wt} . \% \mathrm{C}$ (the other ternary alloys and the two last Hf-rich alloy). All the curves are of the parabolic type, except in the case of the $\mathrm{Ni}-25 \mathrm{Cr}-$ $0.50 \mathrm{C}++\mathrm{Hf}$, the mass gain kinetic of which seems becoming para-linear near the end of the 46 hours. The mass gain curves of the two ternary alloys are very close to one another. The presence of hafnium in the $\mathrm{Ni}-25 \mathrm{Cr}-0.25 \mathrm{C}+\mathrm{Hf}$ alloy obviously led to a mass gain rate reduction by comparison with the corresponding ternary alloy. In contrast, the inverse effect is observed for the $\mathrm{Ni}-25 \mathrm{Cr}-0.50 \mathrm{C}+\mathrm{Hf}$ alloy which oxidized slightly faster than the ternary $\mathrm{Ni}-$ $25 \mathrm{Cr}-0.50 \mathrm{C}$ alloy. The oxidation rate of the Hf-richest $\mathrm{Ni}-25 \mathrm{Cr}-0.50 \mathrm{C}++\mathrm{Hf}$ alloy is higher than for the $\mathrm{Ni}-25 \mathrm{Cr}-$ $0.50 \mathrm{C}+\mathrm{Hf}$, which confirms this effect of hafnium for the $0.50 \mathrm{C}$-containing alloys.

These mass gain files were all treated to specify first a linear $k_{1}$ value (slopes of the straight lines tangent to the mass gain curves at the beginning of the isothermal stage, Figure 2) and a $k_{p}$ value (classical method). The obtained values are given in the two first columns of results in Table 2. There is seemingly no systematic effect of the presence of hafnium on the value of $\mathrm{k}_{1}$ since this one is lower for te $0.25 \mathrm{C}$-containing Hf-rich alloy than for the corresponding $\mathrm{Ni}-25 \mathrm{Cr}-0.25 \mathrm{C}$ alloy while the inverse result is observed between the other alloys $(0.50 \mathrm{C}$ without or with Hf). The same comments can be done about the classically determined $\mathrm{k}_{\mathrm{p}}$ values.

To take into account the mass loss by chromia volatilization, and thus to avoid underestimating the mass gain by oxidation and consequently the chromium-consumption, all curves were also treated according to the $\{\mathrm{m} \times \mathrm{dm} / \mathrm{dt}=$ $\mathrm{k}_{\mathrm{p}}-\mathrm{k}_{\mathrm{v}} \times \mathrm{m}$ \} method. In this type of representation (example of the Ni-25Cr-0.50C-3.72Hf in Figure 3), after an initial part characterized by very high values of the $\{\mathrm{m} \times \mathrm{dm} / \mathrm{dt}\}$ term (on the right), a linear part (elongated cloud of points) appears in the graph for lower values of $\{-\mathrm{m}\}$, as is to say for higher values of $m$. The corresponding values of real $k_{p}$ and of $k_{v}$ were red in the equation of the regression straight line drawn through the linear part of the graph (example in Figure 3). Before any comparison and interpretation these values of $k_{p}$ and $k_{v}$ need to be preliminarily verified. For this, they were tested. This started by drawing the theoretical curves calculated by using either the values of $k_{p}$ classically determined (mass gain plotted versus the square root of time), or the couples of values ( $k_{p}$, $\mathrm{k}_{\mathrm{v}}$ ) determined according to the $\left\{\mathrm{m} \times \mathrm{dm} / \mathrm{dt}=\mathrm{k}_{\mathrm{p}}-\mathrm{k}_{\mathrm{v}} \times \mathrm{m}\right\}$ method. Thereafter the comparison of these two mathematical curves with the experimental curve plotted with the experimental mass gain values acquired for a given alloy, allows verifying whether the values obtained for $\mathrm{k}_{\mathrm{p}}$ (and of $\mathrm{k}_{\mathrm{v}}$ in the second case) well represent the real mass gain kinetic or not. Generally the curves plotted using the $\left(\mathrm{k}_{\mathrm{p}}, \mathrm{k}_{\mathrm{v}}\right)$ couples of constants' values better fitted the experimental curves than the curves plotted using only the classically determined $\mathrm{k}_{\mathrm{p}}$ constant. Indeed, the theoretic 
curve with $k_{p}$ and $k_{v}$ was generally almost superposed with the experimental one. Or at least, the end of the theoretic curve was parallel to the end of the experimental curve (example of the Ni-25Cr-0.50C-3.72Hf alloy in Figure 4).

The values obtained for $\mathrm{k}_{\mathrm{p}}$ and $\mathrm{k}_{\mathrm{v}}$ determined according to the $\left\{\mathrm{m} \times \mathrm{dm} / \mathrm{dt}=\mathrm{k}_{\mathrm{p}}-\mathrm{k}_{\mathrm{v}} \times \mathrm{m}\right\}$ method are given in the two last columns of Table 2 . The $\mathrm{kp}$ values are all globally twice the classical $\mathrm{k}_{\mathrm{p}}$ previously determined for the same alloys. They follow the same variations as the classical $\mathrm{k}_{\mathrm{p}}$ : decrease with Hf for the alloys containing $0.25 \mathrm{wt} . \% \mathrm{C}$ and increase with $\mathrm{Hf}$ for the alloys containing $0.50 \mathrm{wt} \% \mathrm{C}$. In contrast, the variation of $\mathrm{k}_{\mathrm{v}}$ with the presence of $\mathrm{Hf}$ is the same for the two groups of alloys: the volatilization constant increases from the ternary alloy to the Hfcontaining alloy and goes on increasing when the Hf content becomes higher.

\section{Characterization of the Oxidized Surfaces}

The oxidized samples were scanned on their two main faces. The macrographs of one of these two faces are presented in Figure 5. Obviously spallation occurred during cooling essentially for the two ternary alloys on which, after return to room temperature, the external oxide has been lost here and there. This is not the case for the three Hf-rich alloys for which the external oxide scale formed during the oxidation test remained over the whole surface. Hafnium had obviously here the same beneficial effect as usually observed for alloys containing more classical Hf contents.

The surfaces of the oxidized samples were also subjected to X-Ray Diffraction. Two examples are given in Figure 6 for one of the ternary alloys (Ni-25Cr-0.50C) and in Figure 7 for one of the Hf-rich alloys (Ni-25Cr$0.50 \mathrm{C}++\mathrm{Hf}$ ). All diffractograms showed that the main oxide present on the surface of the samples is chromia. However, for the Hf-rich alloys, $\mathrm{HfO}_{2}$ oxides were also detected.

The samples were thereafter covered by electrolytic nickel, cut, embedded and polished. Despite the electrolytic nickel coating, cutting the oxidized samples provoked the loss of a part of the oxides initially present on the external surfaces. However, some oxides remained on surface. Their examination (SEM) and characterization (EDS) were thus possible to do on the metallographic cross-sections (examples in Figure 8). The ternary alloys are effectively covered by chromia. They classically present a carbide-free zone developed from the oxide/alloy interface. Chromia was also the main oxide present on the surface of the Hf-rich alloys but they also contained $\mathrm{HfO}_{2}$ oxides. These later oxides are mixed with chromia in the external scale for some of them, or present in the subsurface as internal oxides. This confirms the results obtained by X-Ray Diffraction and given above. The oxidized Hf-rich alloys present another difference with the ternary alloys: no carbide-free zone developed from the alloy/oxide interface. In contrast with the chromium carbides of the ternary alloys, the HfC carbides did not disappeared in the subsurface; but some of them were locally oxidized. To finish one must also notice that more important internal oxidation seems having started in some locations in the subsurface of the $\mathrm{Ni}-25 \mathrm{Cr}-0.50 \mathrm{C}++\mathrm{Hf}$ alloy.

\section{Characterization of the Bulk Microstructures}

The microstructures in the bulk of the Hf-rich alloys were also examined. They are illustrated by SEM/BSE micrographs in Figure 9, in which the initial as-cast microstructures are also reminded to facilitate comparisons. There was seemingly only a slight decrease in surface fraction of the HfC carbides in the three cases. In addition these carbides were slightly fragmented. Indeed the HfC carbides knew a limited loss of their initial script-like shape and only started to be replaced by aligned small round HfC carbides. However these two phenomena have progressed much slower than for TaC carbides in other alloys (cobalt-based for example) for the same conditions of temperature and duration.

\section{DISCUSSION}

Equiaxed nickel-based superalloys issued from classical foundry were seemingly never considered for the strengthening by hafnium carbides. An efficient reinforcement of such alloys may be though achieved by this way as this can be expected by looking to the microstructures obtained in this work. Indeed, interdendritic script-like HfC carbides mixed with matrix were successfully obtained. This was not initially evident since other script-like MC carbides, tantalum carbides $\mathrm{TaC}$, did not precipitate in so high quantities in nickel-based alloys [4] although their 
carbon and tantalum contents were similar to the carbon and hafnium contents of the alloys studied here. It can be easily supposed that the mechanical strength at high temperature brought by other $\mathrm{MC}$ carbides in other austenitic equiaxed cast alloys (e.g. TaC in cobalt-based alloys [19]) will result from such microstructures for these HfCcontaining nickel-based alloys. But, before studying the mechanical behavior of these alloys at high temperature in hot air it was here verified whether the high Hf contents necessary to develop a dense interdendritic HfC carbides network (similar to the TaC network efficiently reinforcing some cobalt-based alloys) remains still compatible with sufficient oxidation resistance at high temperature.

The answer is that the presence of so high contents in hafnium is obviously not without consequences for these alloys. Indeed the kinetic was always parabolic but it was either accelerated or inversely slowed down, this depending on the carbon content. This may be explained by the fact that a higher carbon content may lead to a better exposure of the interdendritic carbides to oxidation (direct on surface and oxidation of Hf in the external scale, inwards diffusion of oxygen penetrating the alloys to form internal $\mathrm{HfO}_{2}$ oxides), with consequently a slightly faster mass gain in the $0.50 \mathrm{wt} . \% \mathrm{C}$ case than for the corresponding ternary alloys. When the carbon content is lower Hf may influence the oxidation rate as it usually acts when it is present in low quantities (decrease in oxidation rate). The presence of hafnium obviously influences chromia volatilization, an effect which is more difficult to interpret. But one can think in a first time that the presence of hafnium and its oxidation in $\mathrm{HfO}_{2}$ may induce a destabilization of the growing chromia scale. This one may become more sensible to a new oxidation into $\mathrm{CrO}_{3}$, oxide which is gaseous at such very high temperature.

It is not surprising that the well-known effect of hafnium (when present in small quantities in superalloys) on the oxide spallation in case of cooling or varying temperature, was found for the alloys studied in this work. Hafnium obviously led to a significant improvement of the external oxide scale adherence, which can be of great interest in case of thermal cycling as it can be encountered in real industrial applications.

To summarize, the presence of 3.7 or $5.6 \mathrm{wt} . \%$ of hafnium in the HfC form and with an interdendritic repartition is not neutral for the high temperature oxidation behavior of these equiaxed cast chromia-forming nickel-based quaternary alloys. But the changes are not really significant for isothermal oxidation at $1200^{\circ} \mathrm{C}$ in air while there is in contrast a true improvement for the resistance against oxide spallation in conditions of cycling temperature. However it appeared necessary to keep an eye on the Hf-richest alloy which showed a tendency to an early start of linear oxidation, as revealed by the paralinear character of the mass gain near the end of the isothermal stage (after about 25 hours, Figure 2) as well as by the start of significant penetrating oxidation (Figure 8).

\section{CONCLUSION}

These Hf-rich nickel-based alloys have obviously kept the very good behavior in high temperature oxidation of the ternary alloys, thanks to the same high chromium content $(25 \mathrm{wt} . \%)$ but also to the not harmful effect to which the presence in so high quantity of the very reactive element hafnium possibly let think. The high temperature oxidation behavior was still chromia-forming, a character which seems to be not lost soon since the chromium contents, although decreased during these first 46 hours, were still high to ensure the perenity of this chromiaforming behavior. This, with the good volume fraction and morphological behavior of the reinforcing carbides, is favorable to a good sustainability of the high temperature properties of these new alloys. Indeed they are globally oxidation resistant but probably also corrosion resistant thanks to their high chromium contents, and creep resistant thanks to the good stability of the eutectic HfC carbides at high temperature, a creep-resistance which may be better than for TaC-reinforced cobalt-based alloys for which the fragmentation of the $\mathrm{TaC}$ was more severe for similar duration at the same temperature [20]. In contrast with similar cobalt-based alloys containing also high fractions of HfC carbides but not so resistant against high temperature oxidation [21], these alloys are thus ready to be tested at high temperature, without protective coating, to verify the later point: notably specifying their resistance against creep deformation.

\section{ACKNOWLEDGMENTS}

The authors wish to thank Pascal Villeger who has performed the X-Ray Diffraction runs. 


\section{REFERENCES}

1. M. J. Donachie, S. J. Donachie, Superalloys : A Technical Guide (2 ${ }^{\text {nd }}$ Edition), Materials Park: ASM International,

2. D. Young, High Temperature Oxidation and Corrosion of Metals, Amsterdam: Elsevier Corrosion Series, 2008.

3. S. Vasseur, Eur. Pat. Appl. (1992), EP 511099 A1 19921028.

4. P. Berthod, L. Aranda, C. Vébert, S. Michon, Calphad, 28, 159 (2004).

5. P. Berthod, Journal of Alloys and Compounds, 481, 746 (2009).

6. P. Berthod, Materials Science: An Indian Journal, 9(6), 359 (2013).

7. C. Ribaudo, J. Mazumder, Materials Science \& Engineering, A: Structural Materials: Properties, Microstructure and Processing, A120-121, 531 (1989).

8. K. Bouhanek, D. Oquab, B. Pieraggi, Materials Science Forum, 251-254, 33 (1997).

9. E. Nold, G. Ondracek, Praktische Metallographie, 23(6), 268 (1986).

10. Y. G. Kim, Journal of Materials Science, 13(4), 759 (1978).

11. W. R. Witzke, Metallurgical Transactions A: Physical Metallurgy and Materials Science, 7A(3), 443 (1976).

12. B. L. Chen, A. Luo, K. S. Shin, D. L. Jacobson, Refract. Metal. : State-of-the-Art, Proc. Symp. TMS Fall Meet. 65 (1989).

13. A. Luo, J. J. Park, D. L. Jacobson, B. H. Tsao, M. L Ramalingam, Scripta Metallurgica et Materialia 29(6), 729 (1993).

14. A. Luo, J. J. Park, D. L. Jacobson, B. H. Tsao, M. L Ramalingam, Materials Science and Engineering A: Structural Materials: Properties, Microstructure and Processing, 177(1-2), 89 (1994).

15. J. J. Park, D. L. Jacobson, Tungsten Tungsten Alloys, Proc. 1st Int. Conf. 241 (1993).

16. J. J. Park, International Journal of Refractory Metals an d Hard Materials 17(5), 331 (1999).

17. H. P. Gao, R. H. Zee, Journal of Materials Science Letters 20(10), 885 (2001).

18. P. Berthod, Oxidation of Metals 64(3/4), 235 (2005).

19. S. Michon, P. Berthod, L. Aranda, C. Rapin, R. Podor, P. Steinmetz, Calphad 27, 289 (2003).

20. P. Berthod, S. Michon, L. Aranda, S. Mathieu, J. C. Gachon, Calphad 27, 353 (2003).

21. E. Conrath, P. Berthod, Corrosion Engineering Science and Technology, in press, available on-line,(DOI: http://dx.doi.org/10.1179/1743278213Y.0000000105). 
TABLE 1. Chemical compositions of the five nickel-based alloys (SEM/EDS measurements; +/- 1wt.\%)

\begin{tabular}{cccc}
\hline Elements & $\boldsymbol{C r}$ & $\boldsymbol{C}$ & $\boldsymbol{H} \boldsymbol{f}$ \\
\hline $\mathrm{Ni}-25 \mathrm{Cr}-0.25 \mathrm{C}$ & 25 & supposed to be 0.25 & $/$ \\
\hline $\begin{array}{c}\text { Ni-25Cr-0.25C } \\
+ \text { HfC }\end{array}$ & 26 & supposed to be 0.25 & 4.4 \\
\hline Ni-25Cr-0.50C & 26 & supposed to be 0.50 & $/$ \\
\hline $\begin{array}{c}\text { Ni-25Cr-0.50C } \\
+ \text { HfC }\end{array}$ & 26 & supposed to be 0.50 & 4.8 \\
\hline $\begin{array}{c}\text { Ni-25Cr-0.50C } \\
++ \text { HfC }\end{array}$ & 25 & supposed to be 0.50 & 6.6 \\
\hline
\end{tabular}

TABLE 2. Values of the linear constant $\mathrm{k}_{\mathrm{l}}$, of the parabolic constant $\mathrm{k}_{\mathrm{p}}$ and of the constant chromia volatilization constant $\mathrm{k}_{\mathrm{v}}$, the two later ones being derived from the $\mathrm{m} \times \mathrm{dm} / \mathrm{dt}=\mathrm{f}(\mathrm{m})$ plots.

\begin{tabular}{|c|c|c|c|c|}
\hline Constants & $k_{l}\left(\times 10^{-8} \mathrm{~g} / \mathrm{cm}^{2} / \mathrm{s}\right)$ & \multicolumn{2}{|c|}{$k_{p}\left(\times 10^{-12} \mathrm{~g}^{2} \mathrm{~cm}^{-4} \mathrm{~s}^{-1}\right)$} & $k_{v}\left(\times 10^{-10} \mathrm{~g} / \mathrm{cm}^{2} / \mathrm{s}\right)$ \\
\hline method & slope at stage start & classic & $\mathrm{m} \times \mathrm{dm} / \mathrm{dt}=\mathrm{f}(-\mathrm{m})$ & $\mathrm{m} \times \mathrm{dm} / \mathrm{dt}=\mathrm{f}(-\mathrm{m})$ \\
\hline $\mathrm{Ni}-25 \mathrm{Cr}-0.25 \mathrm{C}$ & 89 & 24 & 40 & 68 \\
\hline $\begin{array}{c}\mathrm{Ni}-25 \mathrm{Cr}-0.25 \mathrm{C} \\
+\mathrm{HfC}\end{array}$ & 37 & 12 & 36 & 126 \\
\hline $\mathrm{Ni}-25 \mathrm{Cr}-0.50 \mathrm{C}$ & 25 & 15 & 32 & 93 \\
\hline $\begin{array}{c}\mathrm{Ni}-25 \mathrm{Cr}-0.50 \mathrm{C} \\
+\mathrm{HfC}\end{array}$ & 47 & 20 & 42 & 96 \\
\hline $\begin{array}{c}\mathrm{Ni}-25 \mathrm{Cr}-0.50 \mathrm{C} \\
++\mathrm{HfC}\end{array}$ & 67 & 32 & 68 & 137 \\
\hline
\end{tabular}



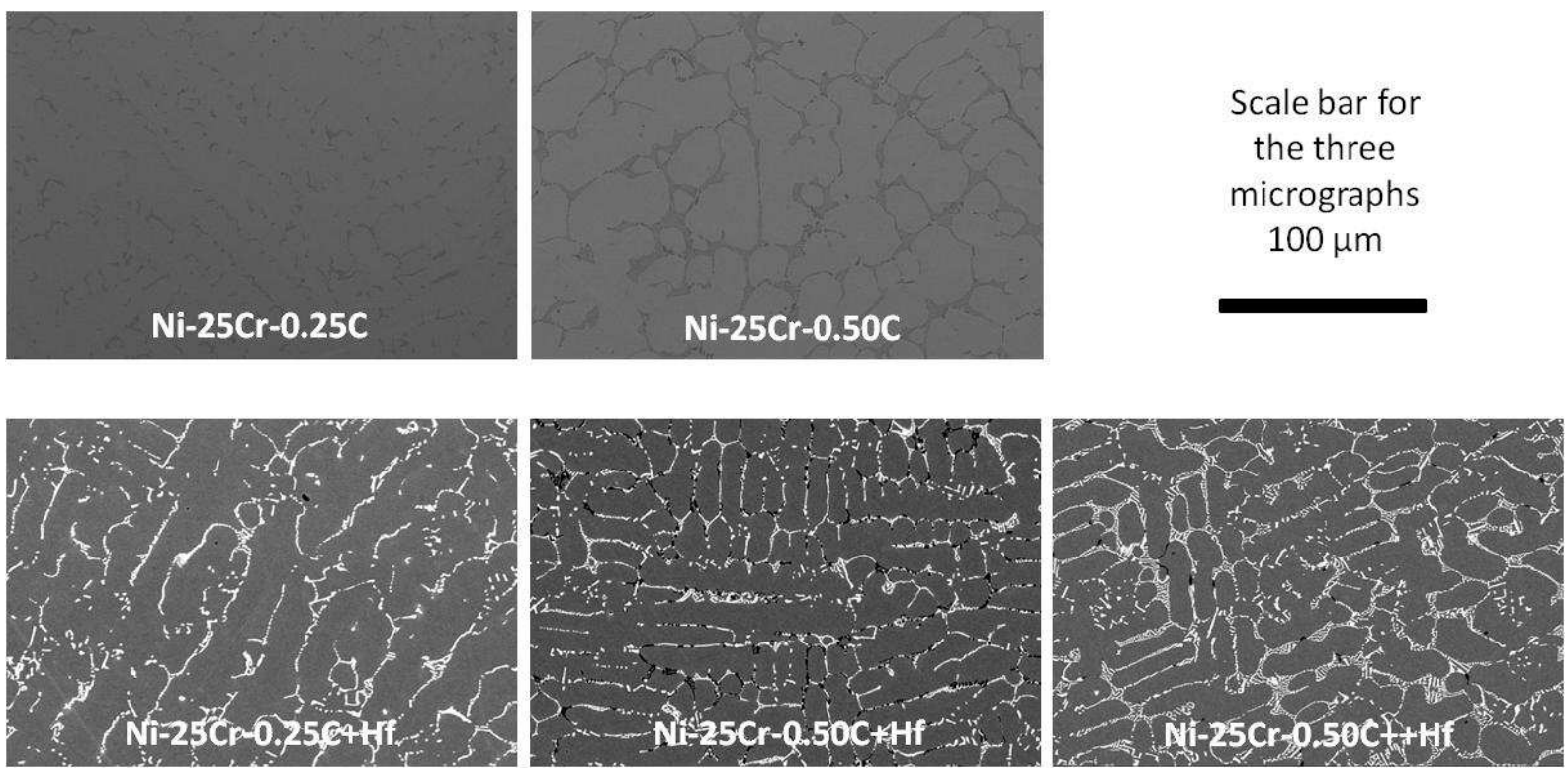

FIGURE 1. SEM/BSE micrographs of the as-cast microstructures of the five studied nickel-based alloys
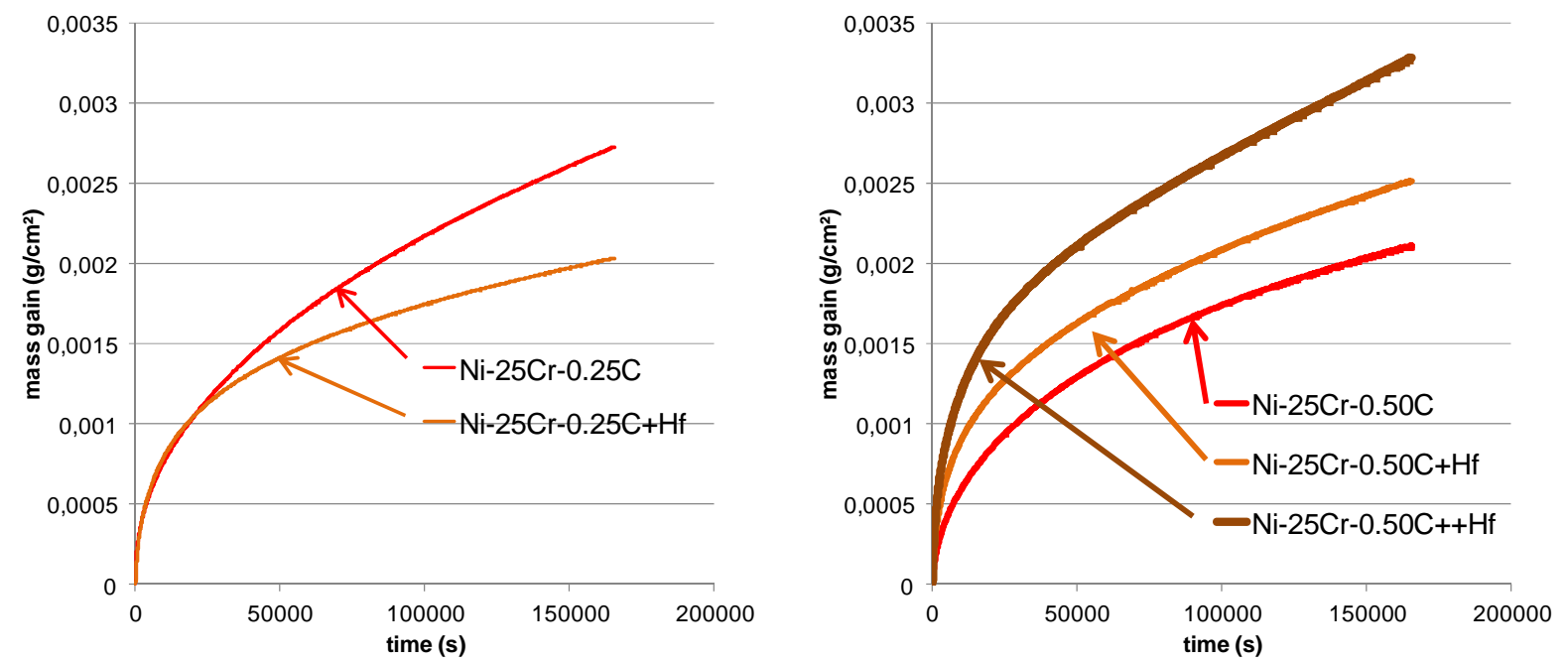

FIGURE 2. The mass gain curves obtained; one the left: for the two $0.25 \mathrm{C}$-containing alloys, and on the right: the three $0.50 \mathrm{C}$-containing alloys 


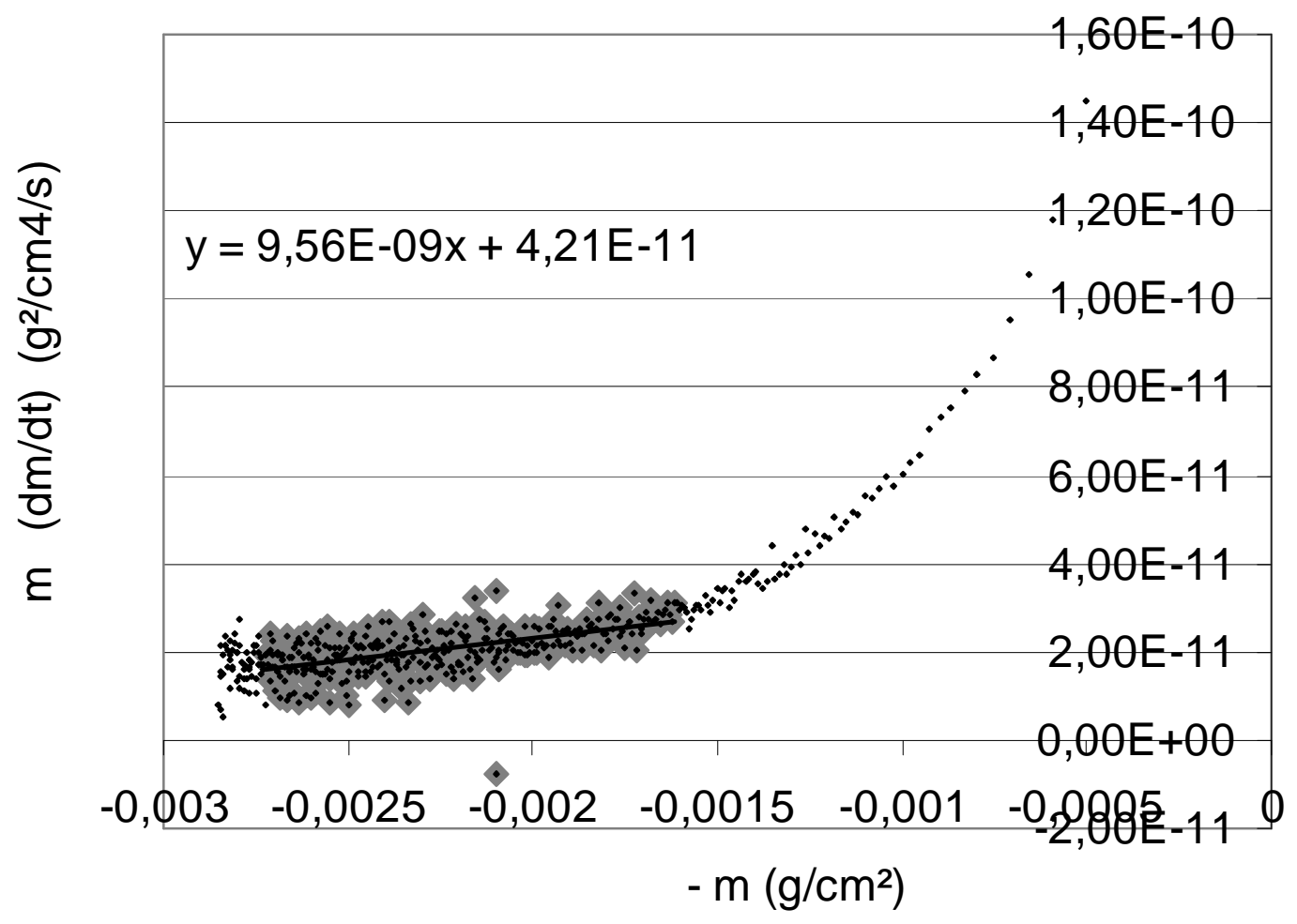

FIGURE 3. Example of treatment of the mass gain results according to the $\left\{\mathrm{m} \times \mathrm{dm} / \mathrm{dt}=\mathrm{kp}-\mathrm{k}_{\mathrm{v}} \times \mathrm{m}\right\} \operatorname{method}[18]$ (here: $\mathrm{Ni}-25 \mathrm{Cr}-0.50 \mathrm{C}+\mathrm{Hf}$ oxidized at $1200^{\circ} \mathrm{C}$ ) 


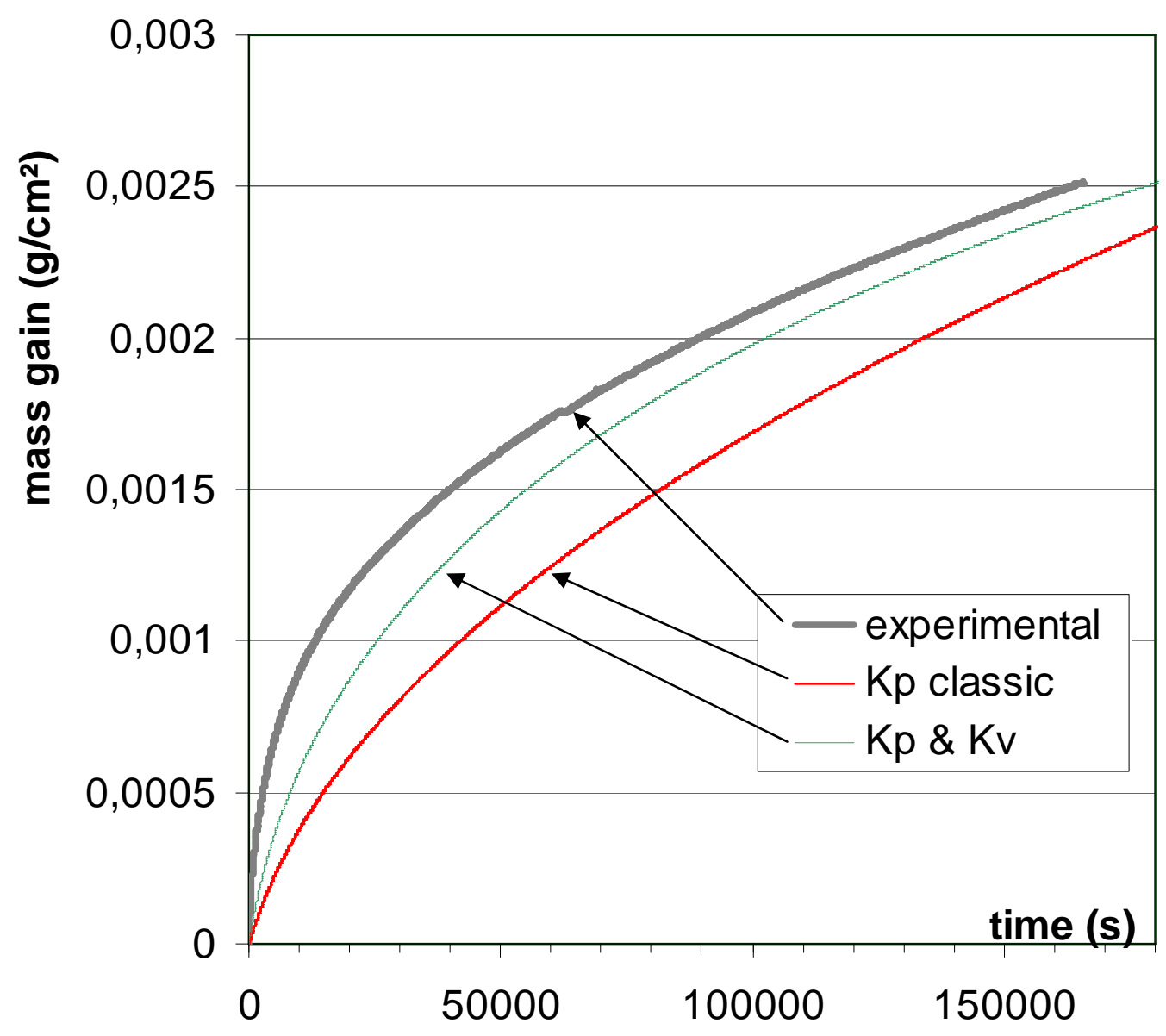

FIGURE 4. Example of test of $\mathrm{k}_{\mathrm{p}}$ value classically determined and of a $\left(\mathrm{k}_{\mathrm{p}}, \mathrm{k}_{\mathrm{v}}\right)$ couple of values resulting from a treatment of the mass gain results according to the $\left\{\mathrm{m} \times \mathrm{dm} / \mathrm{dt}=\mathrm{k}_{\mathrm{p}}-\mathrm{k}_{\mathrm{v}} \times \mathrm{m}\right\}$ method [18]; the best fit with the experimental curve is obtained with the $\left(\mathrm{k}_{\mathrm{p}}, \mathrm{k}_{\mathrm{v}}\right)$ curve (better parallelism of the ends of curves) (here: $\mathrm{Ni}-25 \mathrm{Cr}-0.50 \mathrm{C}+\mathrm{Hf}$ oxidized at $1200^{\circ} \mathrm{C}$ ) 


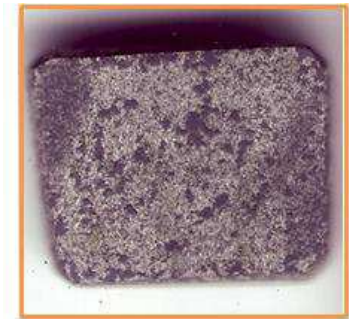

$\mathrm{Ni}-25 \mathrm{Cr}-0.25 \mathrm{C}+\mathrm{Hf}$

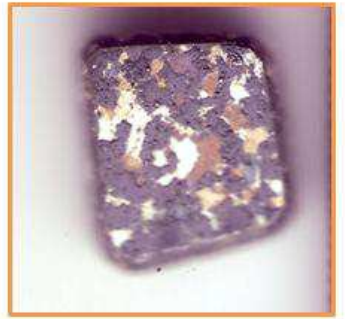

$\mathrm{Ni}-25 \mathrm{Cr}-0.25 \mathrm{C}$

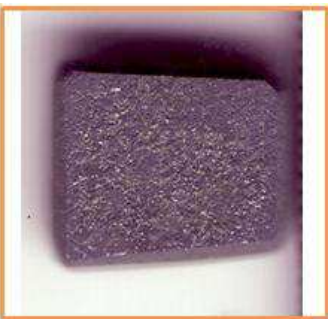

$\mathrm{Ni}-25 \mathrm{Cr}-0.50 \mathrm{C}+\mathrm{Hf}$

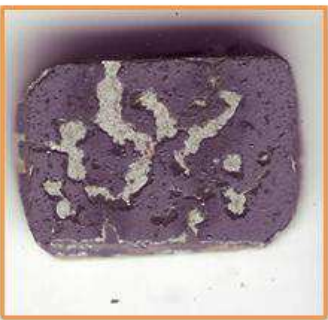

$\mathrm{Ni}-25 \mathrm{Cr}-0.50 \mathrm{C}$

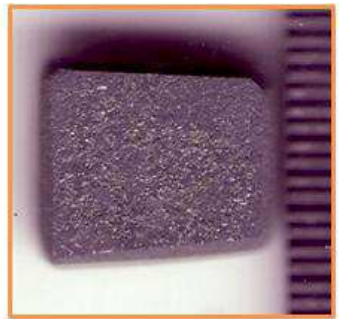

$\mathrm{Ni}-25 \mathrm{Cr}-0.50 \mathrm{C}+\mathrm{Hf}$

$1 \mathrm{~mm}$

FIGURE 5. Aspects of the oxidized alloys after return to room temperature, evidencing the spallation phenomenon which has affected the Hf-free ternary alloys and not the Hf-rich ones 


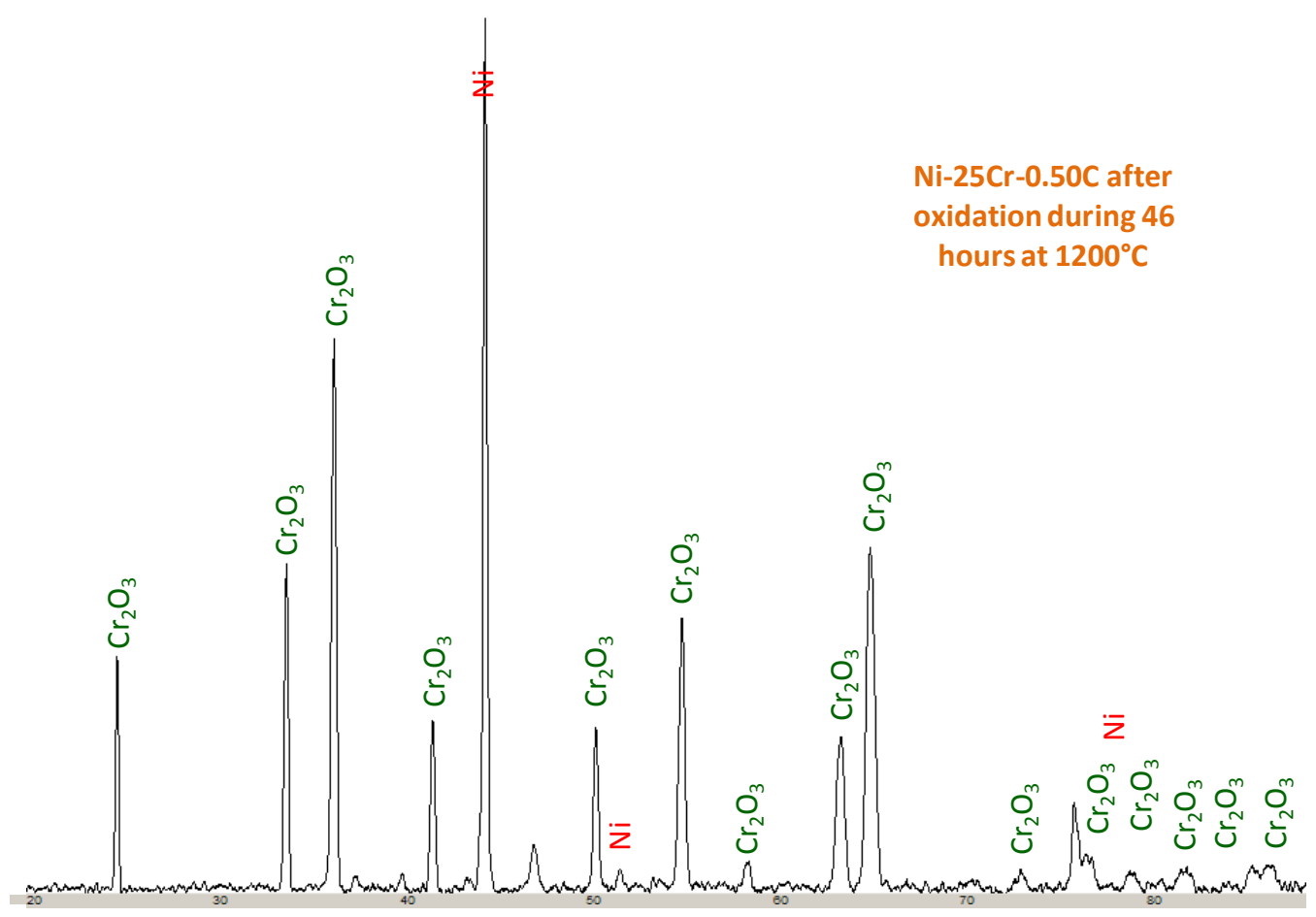

FIGURE 6. Diffractogram of the Ni-25Cr-0.50C alloy after $46 \mathrm{~h}$ of oxidation at $1200^{\circ} \mathrm{C}$

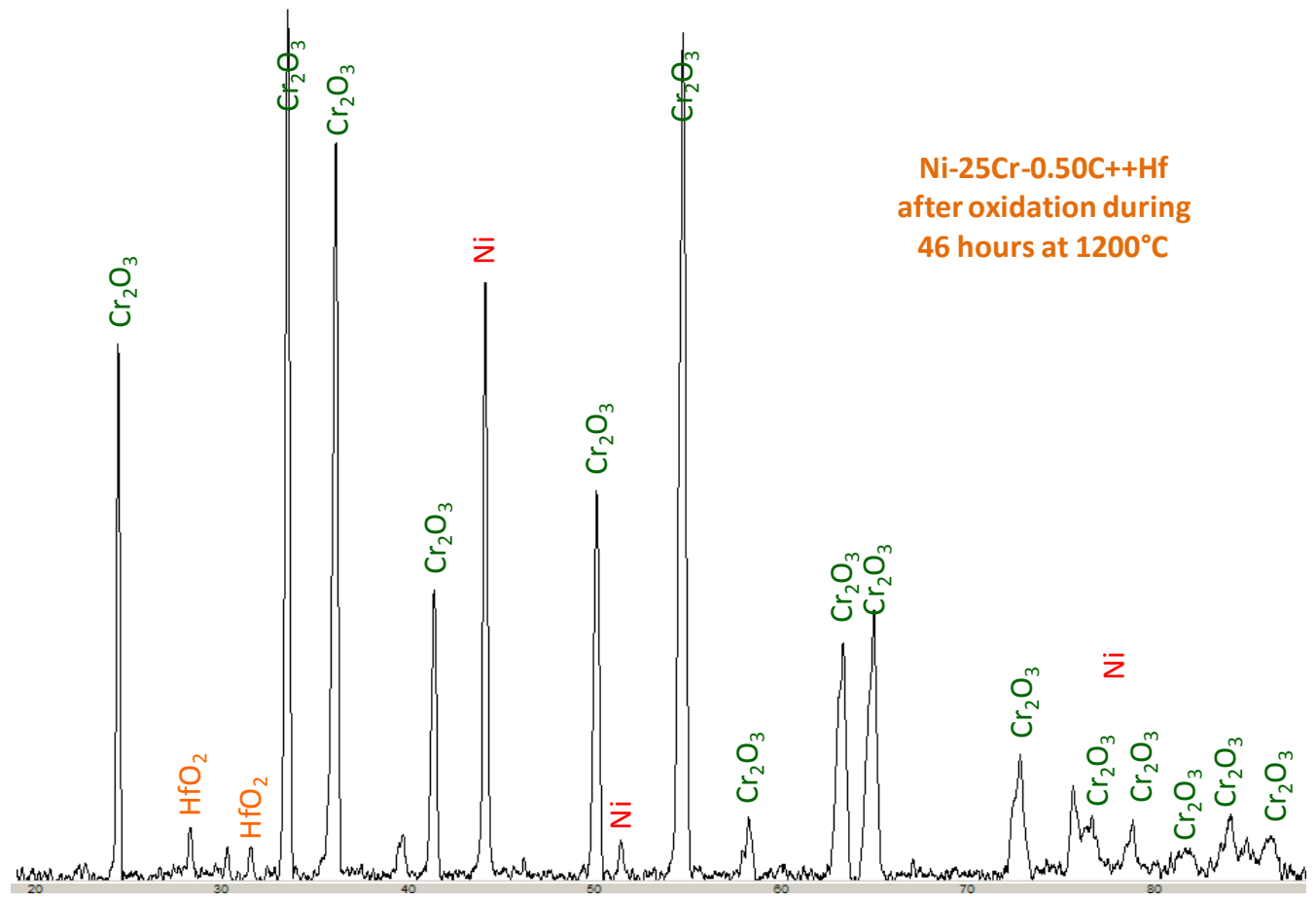

FIGURE 7. Diffractogram of the Ni-25Cr-0.50C alloy after $46 \mathrm{~h}$ of oxidation at $1200^{\circ} \mathrm{C}$ 

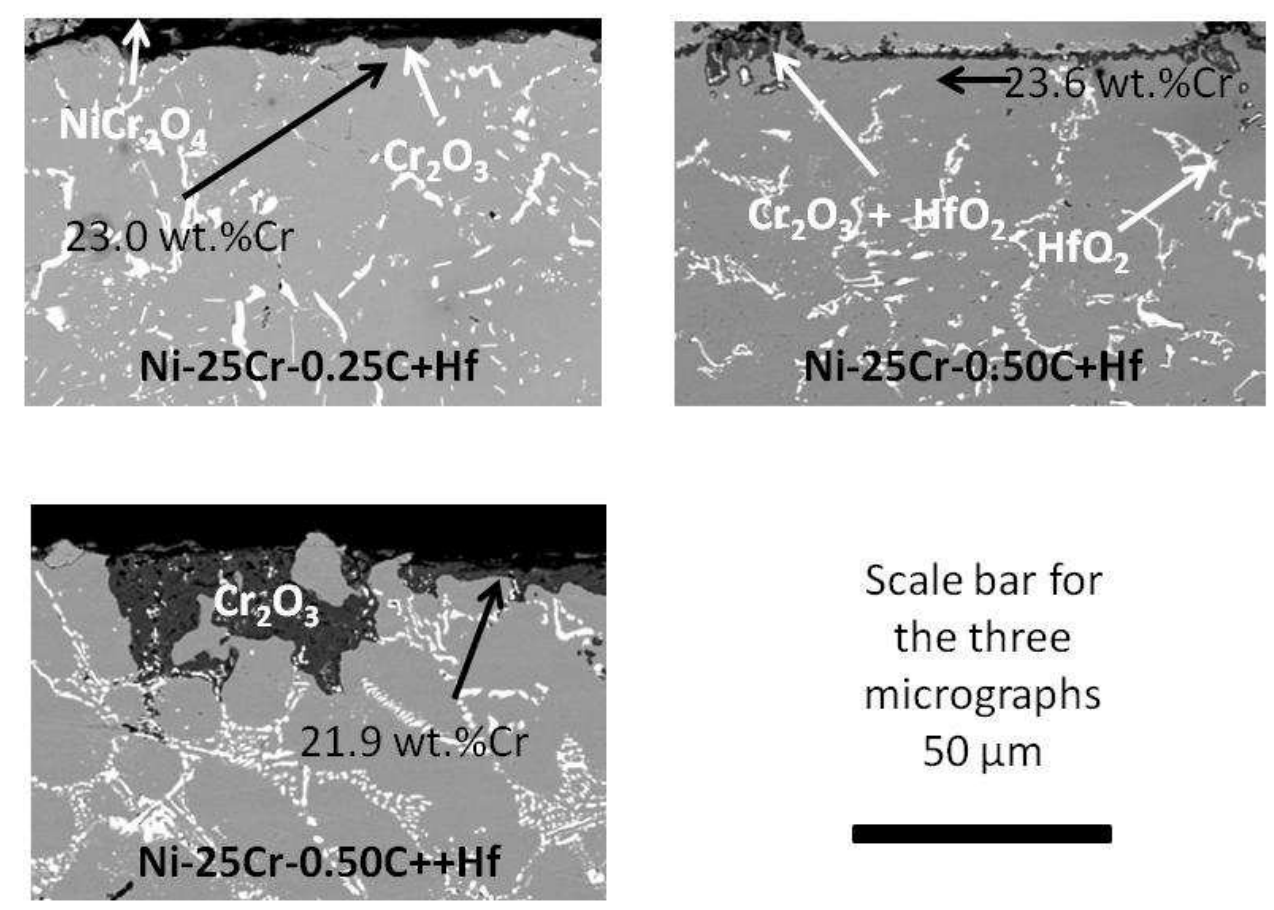
Scale bar for the three micrographs
$50 \mu \mathrm{m}$

FIGURE 8. SEM/BSE micrographs of the oxidized surfaces of the Hf-rich alloys
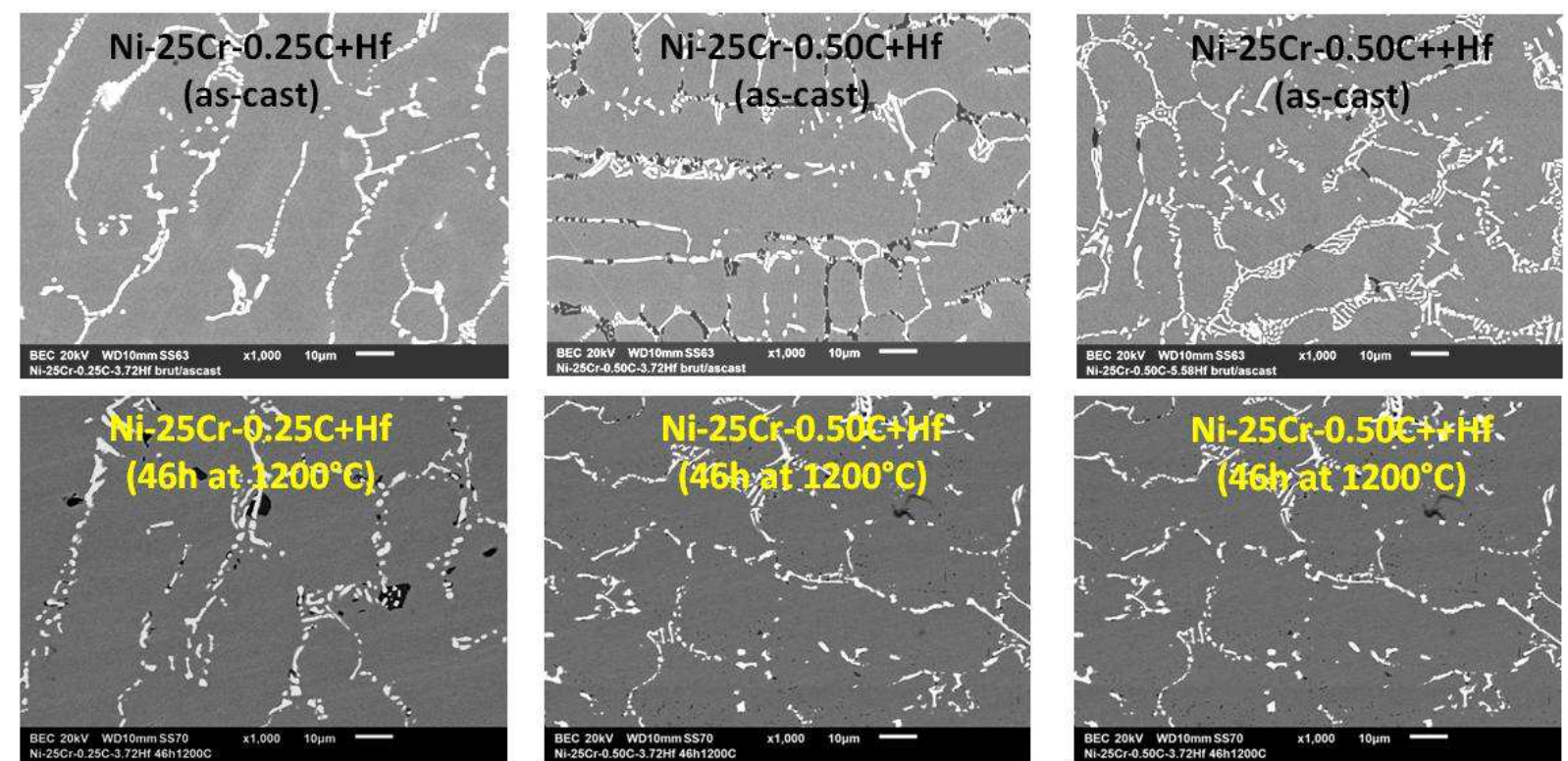

Scale bar for the three micrographs:

$50 \mu \mathrm{m}$

FIGURE 9. SEM/BSE micrographs of the bulk microstructures of the Hf-rich alloys 